\title{
CATARSIS LIBERADORA Y TRADICIÓN RESUMIDA: LAS NUEVAS FRONTERAS DE LA REALIDAD EN LA NARRATIVA URUGUAYA CONTEMPORÁNEA
}

\author{
POR \\ FERNANDO AINSA \\ (UNESCO)
}

Todo análisis del proceso narrativo uruguayo de los últimos años debe pasarinicialmente por una referencia a los macro-esquemas que han condicionado su discurso cultural, sobre todo durante el período de facto que va del 27 de junio de 1973 al 1 de marzo de 1985. En esos doce años de dictadura, fenómenos como la censura, la represión, el exilio y las diferentes formas de resistencia interna, marcaron de tal modo la vida creativa, que buena parte de la narrativa se ha visto obligada a "situarse" coyunturalmente en relación a "esa" historia. Ello se ha traducido en la primacía de una temática inevitablemente contextualizada y en una valoración crítica que no podía prescindir de las categorías extraliterarias que marcaban la propia producción ficcional, esquema del que se emerge ahora, felizmente, pero no sin dificultades.

Por esta razón, la periodización y la presentación de generaciones, movimientos y autores, no puede basarse únicamente en tendencias estéticas y necesita de una primera referencia a los grandes "cortes" históricos del período, donde los acontecimientos socio-políticos se superponen a los culturales y marcan jalones comunes. Aún desde la perspectiva de la libertad creativa ahora vigente, ${ }^{1}$ todo panorama crítico, como el que nos proponemos desarrollar en estas páginas, necesita partir de estos referentes contextuales. A tal efecto hemos organizado nuestro análisis a partir de tres ejes histórico-literarios:

1) El que va desde mediados de los años sesenta hasta la ruptura democrática del 27 de junio de 1973, fecha del golpe de estado. Es éste un período de euforia y crisis, caracterizado por un intenso experimentalismo literario en lo formal y un maximalismo voluntarista y principista en lo político, en general

1 El proceso inaugurado en 1985 y vigente hasta la fecha ha sido favorecido por una indiscutible libertad de prensa y la multiplicación de órganos periodísticos (diarios, semanarios, suplementos y revistas mensuales), la reactivación de la industria editorial con el surgimiento de nuevos sellos y el impulso de los que atravesaron con dificultades el período militar. Y ello, aunque se sospechen a fines de 1991 algunos signos de "morosidad" y "cansancio", especialmente en las promociones más jovenes que, indudablemente, están buscando otras vías de expresión que la de sus mayores. 
bien diferenciados, aunque muchas veces practicados paradójicamente por el mismo autor. Es ése el momento en que surge una nueva generación de narradores que se reconoce en la vasta renovación delas letras latinoamericanas del período.

2) El periodo de la dictadura entre el 27 de junio 1973 y el 1 de abril de 1985. Son éstos años de dispersión, exilio, y resistencia activa o pasiva y, a partir de 1984, de retorno y restablecimiento del diálogo entre la cultura del "interior" y la producida en el exterior. ${ }^{2}$ Las experiencias formales se decantan y se recuperan raíces culturales olvidadas, dejadas de lado o simplemente ignoradas. Al mismo tiempo, una visión "sesgada", cuando no grotesca o marcada por el absurdo, se incorpora y enriquece al realismo tradicional, especialmente en la narrativa de temática urbana. El fenómeno se evidencia entre los autores más jóvenes, menos trascendentes y categóricos en sus afirmaciones que los autores de los años 45 y 60 .

3) El análisis panorámico de las tendencias, el proceso y la temática de la narrativa uruguaya contemporánea que proponemos en las páginas siguientes se estructura alrededor de estos dos polos, pese a que en los últimos años se adivina el surgimiento de un "revisionismo" que cuestiona valores fijados en el pasado, lo que anuncia un tercer período de catarsis liberadora y tradición. reasumida.

\section{MACRO-ESTRUCTURAS CONDICIONANTES DEL DISCURSO NARRATIVO DE LOS AÑOS 60}

Alrededor de 1972 podía decirse que una aventura inédita en las letras uruguayas estaba en marcha. Los autores jóvenes de aquel momento, llamados de la Generación del 60 o de "la crisis", ${ }^{3}$ ingresaban a la narrativa munidos de un sólido bagaje intelectual. Se habían formado en la mejor tradición europea y norteamericana y descubrían la eclosión de la literatura latinoamericana a escala continental. Sin embargo, percibian al mismo tiempo los indicios del deterioro del sistema en el que habían crecido y optaban por los cambios que parecian ineluctables a escala de un Tercer Mundo, cuyos signos se reconocían en la búsqueda de una identidad común.

Este carácter dual y, a veces, antinómico -apertura en lo artístico y opciones definidas, cuando no unilaterales, en lo político- marcaría, no sin

\footnotetext{
${ }^{2}$ Las jornadas de estudio Franco-Umiguayas celebradas en París en el mes de noviembre 1987, en el marco de la Sorbonne, la Unión Latina y la UNESCO, constituyen un buen ejemplo de cómo se opero el restablecimiento del diálogo.

${ }^{3}$ "Los nuevos" los llamó Emir Rodríguez Monegal, Generación de "la crisis", los bautizó Ángel Rama; Generación del60, prefirieron auto-denominarse sus integrantes, conscientes de la relatividad de las fechas y los criterios generacionales y del enfasis excesivamente actual, por no decir periodístico, de las etiquetas de E.R.M. o A.R.
} 
contradicciones, un discurso creativo que estaba al día en lo "formal" y en las modalidades expresivas y estéticas, pero que estaba, al mismo tiempo, condicionado por las macro-estructuras socio-políticas existentes. La "perspectiva jubilosa" con que a fines de los años sesenta se miraba el futuro del Uruguay en el marco de una América Latina en ebullición revolucionaria, no impedía que los jóvenes autores leyeran atentamente lo mejor de la producción literaria del continente, de Estados Unidos y de Europa (especialmente el nouveau roman), sin el temor ni la angustia que las influencias foráneas pudieran provocar en un discurso tan marcado y condicionado en lo político y social. Se acaparaba lo mejor de técnicas y procedimientos ajenos para ponerlos al servicio de una preocupación nacional inscrita en la problemática de un continente que buscaba sus propios modos de expresión identitaria. La entusiasta asimilación de unos se traducía en contradicciones no resueltas por otros.

La "línea creciente entre tensión y exigencia", como fuera definida en un estudio sobre "Los nuevos narradores", publicado en $1968^{4}$-formalizaba una apuesta que se traducía en la efervescencia de revistas, páginas culturales en diarios y semanarios y en las editoriales que florecieron con un novedoso rigor profesional y una estimulante competividad (Alfa, Arca y Banda Oriental, sobre todo), alimentando una producción autosuficiente y cerrada sobre el país. Montevideo era un apasionante "micro-cosmos" donde nadie escribía "para ser traducido", como declaraba con ironía Mario César Fernández, autor de una colección de relatos titulados precisamente Industria nacional (1966). Los signos en que podía reconocerse esa singularidad generacional eran variados.

\section{LA REALIDAD COMO COMPLEJIDAD}

Para los jóvenes autores del 60 , la buena narrativa no tenía por qué ser típica y folklórica, ni lo popular era siempre sinónimo de bueno. La indagación de la realidad no tenía por qué hacer de lo cotidiano algo trascendente para justificar cualquier compromiso. La exigencia literaria llevaba a que las correspondencias y las preocupaciones formales se imbricaran intensamente con la realidad, al punto de que los distingos clásicos entre forma y contenido ya no tenían razón de ser ni eran planteados por ninguno de los nuevos narradores. Se trataba de romper un cierto esquema que oponia tradicionalmente la narrativa urbana a la campesina y de incorporar una cierta complejidad a personajes que no tenían por qué ser siempre oficinistas o representantes de una clase media sin mayores ambiciones. Una novela podía traducir una "unidad compleja" y un "encuentro de tensiones", donde arte y compromiso se conjugaran en el mismo tiempo novelesco. Se buscaba la autenticidad a partir del rigor y las exigencias formales, y no se desdeñaba la complejidad de la realidad en nombre de la facilidad o la simplificación maniquea de un esquema

${ }^{4}$ Mercedes Ramirez de Rosiello, Capitulo Oriental 38 (Buenos Aires/Montevideo: Cedal, 1968), 603. 
político, tal como podían reflejarlo en ese mismo período otros géneros, como el ensayo, las crónicas periodísticas y las proclamas y panfletos.

La coincidencia y la co-existencia de estas contradictorias oposiciones, dieron una inusual variedad a la joven narrativa uruguaya de esos años, cuyos primeros libros se editaron en el espacio de apenas tres años, entre 1962 y 1965. Sin embargo, aunque empezaron a publicar en el mismo período, la edad de los autores no era precisamente un factor de unidad, ya que una diferencia de más de diez años podía separar a algunos de sus integrantes. La singularidad generacional venía marcada por otros factores.

Los nombres de Hugo Giovanetti Viola, Gustavo Seija, Jorge Onetti, Juan Carlos Somma, Eduardo Galeano, Juan Carlos Legido, Sylvia Lago, Jorge Sclavo, Ariel Méndez, Manuel Márquez, Mario César Fernández, Jorge Musto, Walter Pedreyra, Hiber Conteris, Cristina Peri Rossi (grupo en el que me sitúo personalmente como escritor) coexistían en el seno de una generación, más allá de las respectivas edades de sus integrantes, gracias a una serie de obras donde el rigor literario se unía al convencimiento de que esa sería la "década de la liberación" en lo político. Pese al maximalismo de los planteos, el provindencialismo con que se esperaballevarlos a cabo y las excesivas esperanzas políticas, estimuladas por la influencia de la revolución cubana, no llevaron fuera de algún caso aislado- a confundir "la literatura de la revolución" con la necesaria "revolución en la literatura", importante distingo que había hecho Julio Cortázar en su polémica con Oscar Collazos, y que fuera casi unánimemente tenido en cuenta por los autores jóvenes. La exigencia formal no eliminaba la preocupación impuesta por una realidad en tensión, sino que, por el contrario, se transformaba en su mejor incentivo.

\section{CONTINUIDAD DEL RIGOR INTELECTUALIZADO}

Pese a los signos que la distinguían, la generación del 60 no se caracterizó por las grandes rupturas que habían podido vivirse en generaciones anteriores, como en la del 900 (José Enrique Rodó, Julio Herrera y Reissig y los narradores Carlos Reyles, Javier de Viana y el joven Horacio Quiroga), en la de 1930 y en la acerbamente polémica del 45. El severo revisionismo crítico de Emir Rodríguez Monegal y Ángel Rama contra sus predecesores, sobre todo el fundador de la crítica y la historiografia literaria del Uruguay, Alberto Zum Felde, que habían marcado una época -la del surgimiento de la Generación del 45- no tiene en los sesenta a sus renovados "parricidas".

Las polémicas sobre el facilismo y la insustancialidad poética ("poesia de corzas y gacelas" y el llamado "casalismo ${ }^{m_{5}}$ ), la condena de una cierta literatura

\footnotetext{
${ }^{8}$ La ausencia de rigor crítico y de una crítica literaria responsable y orientadora, fueron las acusaciones de la Generación del 45 contra sus mayores. El ejemplo de la revista Alfar, dirigida por el poeta Julio J. Casal, fue convertido en el símbolo paradigmático del elogio fácil y el "amiguismo" que había que combatir y desterrar, pero que, en realidad, se traduciría en la creación de cerrados cenáculos.
} 
"oficialista" y la reivindicación de un lúcido rigor intelectualizado poco proclive al lirismo o a los sentimientos abiertamente expresados que definieron a la Generación del $45,{ }^{6}$ no se repitieron bajo ese u otro signo en la del 60 , pese a que no faltaron los gérmenes de las diferencias. Basta citar como ejemplo el rechazo que provocaba entre los jóvenes el "nuevo facilismo" y el estereotipamiento de la literatura de autores como Mario Benedetti y los recelos que le provocaron a éste el presunto formalismo y la marginalidad de algunos narradores de los años $60 .^{7}$

Si un esbozo de polémica se anuncia en algún momento, es la reflexión solidaria ante el resquebrajamiento del sistema social y político, y la creciente hostilidad de la reacción que crecía en el país por esos años, la que lleva a la inevitable coexistencia entre las generaciones del 45 y del 60 . La crisis larvada del sistema y la ruptura institucional de junio de 1973, con la consiguiente pérdida de una larga tradición civilista y democrática uruguaya, hizo volar en pedazos las divisiones que podían enfrentar en lo literario a escritores de generaciones diferentes. Otras preocupaciones debieron unirlos, antes y después, por sobre cualquier diferencia estética. Las divisiones y las solidaridades se basaban en otros criterios.

La sombra tutelar y preocupada de los novelistas mayores, como Juan Carlos Onetti, Carlos Martinez Moreno y Enrique Amorim (prematuramente fallecido en 1960) o la de intelectuales como Jesualdo y Carlos Quijano, se prolongaba como un "magisterio" sin rupturas sobre las décadas, hasta un presente donde se mezclaban ambiguamente los sentimientos de pesimismo y esperanza de "padres e hijos" unidos por una misma alarmada preocupación: el "naufragio" colectivo que se avecinaba.

La joven Generación del 60 se inscribía, pues, en la tradición de rigor intelectual, preocupación formal y compromiso con la realidad de sus mayores y, más allá de las diferencias estéticas entre autores, garantizaba una continuidad en la que la diversidad era la garantía de una polifonía expresiva polivalente y no el resultado de una confrontación generacional.

\footnotetext{
'En "Los novelistas del 45" (Capttulo Oriental 33; Montevideo/Buenos Aires: Cedal, 1968, 513-528) y en Tiempo reconquistado por Fernando Ainsa (especialmente en "Los lúcidos partes de un naufragio colectivo") (Montevideo: Editorial Géminis, 1977), hemos analizado en detalle las características de la narrativa del 45.

7 "Literatura de balneario", calificó con tono alarmado Mario Benedetti a una serie de novelas de Jorge Musto, Alberto Paganini, Hiber Conteris y a mi propia novela El testigo (1964), considerando que centrar la narrativa en esos escenarios de la costa era un modo de fugarse "de otros temas, otras urgencias, otras osadias". Veía en esa obras un exceso de influencia de Pavese, Duras, García Hortelano o de los films de Antonioni, donde el aburrimiento y la marginalidad se le aparecían como posturas más intelectuales que vitales.
} 


\section{NUEVOS TEMAS PARA UNA MISMA PREOCUPACION}

Sin embargo, la solidaridad con sus predecesores no se traduce en un ejercicio creativo alrededor de una misma temática. La narrativa del 60 supera los esquemas tradicionales del enfrentamiento entre un campo estereotipado y la ciudad de los apacibles "montevideanos", creando personajes más complejos que los arquetipos del "paisano" y el "empleado público". La ficción aborda territorios hasta ese momento inéditos.

Si se anuncia esa apertura temática en algunas obras de autoresintegrantes de la generación anterior, como Carlos Maggi, Carlos Martínez Moreno, y Clara Silva en Aviso a la población (1964), es Eduardo Galeano quien intuye la dimensión que ofrecía la nueva realidad al novelar en Los fantasmas del día del león (1967), las últimas horas de tres pistoleros famosos sitiados por la policía. Este relato, basado en un hecho real que había conmovido a la opinión pública, resultó premonitorio de la violencia a la que se enfrentaría el Uruguay poco después. La tensión que precedía a la masacre de esos delincuentes aparecía reflejada en toda su crudeza y en un estilo sin concesiones. En 1978, ya viviendo en el exilio, Galeano escribiría Días y noches de amor y de guerra, donde esa misma prepotencia policial se había puesto al servicio de la represión dictatorial. Los "delincuentes" perseguidos ya eran otros. Los medios utilizados, idénticos.

No menos premonitorio resultaría El acecho (1971) de Walter Pedreyra, donde el frenesí ciego y polarizado de la palabra (comunicados, informativos radiales, discursos, diálogos, gritos y proclamas) anuncia, en una serie de relatos de ritmo alucinado, la violencia real agazapada en un sistema ya resquebrajado.

Por su parte, Sylvia Lago en Los días dorados de la señora Pieldediamante (1971), incursiona en los vericuetos de la hipocresía sexual y social de la clase aita, y autores como Jorge Musto, comprometidos cabalmente con la realidad circundante, no dudan en escenificar sus obras en melancólicos balnearios de la costa uruguaya, como haría en Un largo silencio (1965). El mismo Musto, se burlaría con eficacia de las ironías del destino en una novela de estructura casi policial, Noche de circo (1966) y con idéntica sobriedad y sin ninguna concesión a la retórica o a la proclividad demagógica que el tema podría procurarle, narraría en $E l$ pasajero (1977) una experiencia de guerrilla urbana, la lucha contra la dictadura, la tortura, la cárcel y el exilio.

La ciudad, primero apaciblemente y luego en las tensiones que descubría no sin asombro (titulé una de mis novelas justamente, Con cierto asombro (1968), era colonizada por la ficción, siguiendo los primeros pasos de los escritores de una generación anterior, como Dionisio Trillo Pays, Anderssen Banchero, Juan José Lacoste, Mario Benedetti en Montevideanos y Ariel Méndez en La ciudad contra los muros y La encrucijada.

El punto de vista múltiple, el monólogo interior, la estructura novelesca elaborada, se incorporaban de pleno derecho a las técnicas narrativas manejadas 
con destreza por ávidos lectores de la mejor producción de la literatura universal. Pero más allá del dominio de una herramienta, como ya lo hacian con soltura y sutileza autores de una primera obra como el citado Jorge Musto y Gustavo Seija (La cantera, 1970), se adivinaba en muchas páginas el trasfondo de sentimientos y pasiones desterradas como inoperantes por los "lúcidos" del 45, clamando por un digno retorno a las letras. Si ello se percibe en Los museos abandonados (1968) de Cristina Peri Rossi y en la tierna historia de Trajano (1960) de Sylvia Lago, es evidente en la línea que se afirma también en la angustia de rá́z religiosa de Clonis (1961) y Forma de piel (1967) de Juan Carlos Somma, en La rabia triste (1972) de Hugo Giovanetti Viola y en la piedad no exenta de humor de César Di Candia (El evangelio según Lucía, 1969).

\section{UNA LITERATURA MARGINAL REPRESENTATIVA}

Pero si éstas eran las grandes corrientes en que se expresaban algunos, iba creciendo, mientras tanto, una sólida narrativa en apariencia marginal, pero en la que podía reconocerse una larga tradición de la literatura rusa del siglo XIX, especialmente Gogol, Chejov y Dostoievsky y de la europea del siglo XX, como Kafka, Céline y Barbusse. "Los pequeños seres", el mundo del "subsuelo", los oscuros funcionarios, los "maniáticos" y tiernos personajes que inspiran tanto afecto comorepugnancia, surgen y proliferan en la narrativa uruguaya, reflejando la compleja composición social del país, con una inmigración proveniente de todas las culturas. La tipología maniquea del pasado cede a un ahondamiento en los abismos de un alma que se revela rica y compleja, controversial y desgarrada.

En ese contexto, la literatura fantástica que se aborda directa o tangencialmente, no aparece como una forma de evasión, sino como un enriquecimiento y ensanchamiento de la realidad. Las posibilidades subversivas de lo imaginario se afianzan en una línea original de expresión, donde la separación cronológica entre autores se esfuma aún más. Si Felisberto Hernández ha trascendidolas fronteras del Uruguay y hoy es reconocidointernacionalmente gracias a Julio Cortázar e Italo Calvino, una serie de autores que cabalgan entre las generaciones del $45 \mathrm{y}$ del 60 abre las puertas a una dirección renovada y original de las letras uruguayas contemporáneas. En este grupo deben mencionarse Armonía Somers, L.S. Garini y Julio Ricci.

La obra narrativa de Armonía Somers se construye, casi secretamente, a partir de un realismo tenso y exasperado, rozando lo extraño y fantástico o incursionando en temasinéditos. La mujer desnuda (1951) y Muerte por alacrán (1978) son dos excelentes ejemplos, completados por Sólolos elefantes encuentran mandrágora (1986). Sin embargo, su original universo, donde la realidad se percibe en forma "sesgada", ${ }^{8}$ está integrado por un conjunto de obras de tono

${ }^{8}$ Nicasio Perera San Martín, introducción a la traducción al francés de Muerte por alacrón, Arcane 17 (Nantes), 1987. 
insólito y obsesivo: El derrumbamiento (1953), La calle del viento norte (1963), De miedo en miedo (1963), Un retrato para Dickens (1969) y Tríptico darwiniano (1982).

El caso de L.S. Garini es aún más marginal. Autor de dos conjuntos de relatos, Una forma de la desventura (1963), Equilibrios y otros desequilibrios (1979), Garini aborda situaciones cotidianas en las que, a través de una reiteración insistente, la realidad se crispa hasta el absurdo. Personajes de los que poco se sabe actúan de una manera imprecisa, llena de variantes (todas ellas posibles), diluyendola normalidad en extrañeza, nuevo territorio de la narrativa en el que se identifican hoy otros escritores (Gley Eyherabide, Héctor Galmés, Walter de Camilli, Juvenal Botto y Miguel Ángel Campodónico).

Julio Ricci ha reconocido lealmente su deuda con Garini, a cuya casa, situada en las afueras de Montevideo, concurría con un grupo de escritores de la generación del 60. Sin embargo, aunque la temática sea similar y puedan trazarse paralelos entre las situaciones escatológicas que rozan el mal gusto y las "manías" de los "pequeños seres" de ambos narradores, Ricci ha estructurado un mundo propio a través de seis volúmenes de cuentos de temática y estilo unívocos, escalonados paciente y obsesivamente a través del tiempo: Los maniáticos (1970); El grongo (1976); Ocho modelos de felicidad (1980), Cuentos civilizados (1985), Los mareados (1987) y Cuentos de fe y esperanza (1990).

Un lector de Ricci reconoce sin dificultad a sus cuentos. Son inconfundibles la atmósfera, la temática, el "personaje" construido alrededor de una situación absurda, cuando no humillante, episodios menores, si no abiertamente escatológicos, disimulados generalmente en la vida cotidiana, que se retrazan aquí con regodeo morboso, temática y "palabra hedionda" que nos atrevemos a llamar una verdadera "estética de lo asqueroso" al modo de la "comunicación excrementicia" de Swedenborg. Sin embargo, la galería de protagonistas de Ricci (emigrantes centro-europeos, marginales de toda índole, maniáticos y raros), están empapados de una profunda y aterida soledad, anhelo de ternura que los convierte en verdaderas "almas muertas" rioplatenses. Parejas

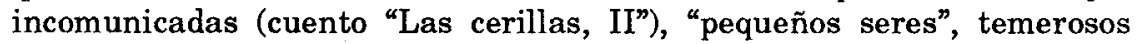
funcionarios ("La pared", "La necesidad de ser esquizofrénico", "La jerarquía", "El cronista de obituarias", "El gerente" y "La baba"), personajes inmersos en la abyección recorren los cuentos falsamente "civilizados" y viven en un universo opresivo de pequeñas miserias acumuladas hasta la desesperación, lejos de los "modelos de felicidad" pregonados irónicamente.

Con Ricci se representa, a través del grotesco, de lo ácidamente burlón y en el recuento de las miserias de la mediocridad que nos rodea, un mundo literario replegado sobre sí mismo para protegerse contra el sistema instaurado, llámese burocracia, egoísmo, jerarquía o meros convencionalismos. El ejemplo de $E l$ grongo (1976) es casi paradigmático y se convierte en un símbolo de los años de la dictadura durante los cuales Ricci publica buena parte de su obra. Una verdadera literatura "del subsuelo" uruguayo hecha de pasiva oactiva resistencia 
se gesta a partir de esa especie de monstruoso "Leviatán" criollo que, sin solazarse en lo abyecto, funda una verdadera "estética de lo asqueroso".

\section{ENTRE LA DIÁSPORA Y LA REAPERTURA}

1973 no es una fecha literaria, pero marca la ruptura de una continuidad y la abrupta división, más allá de cualquier opción política, entre los que se van exilados voluntaria o forzadamente y los que se quedan en el país. A partir de las experiencias que conllevan las alternativas vitales del exilio, se perciben las inflexiones en el discurso narrativo uruguayo enunciado en México, Argentina, Brasil, Cuba, y Venezuela, en el caso de América Latina; en España, Francia, Italia, las dos Alemanias - Federal y Democrática-, Suecia y en tantos otros puntos de una cartografía universal del exilio uruguayo, ${ }^{9}$ discurso complementario de la creación en el interior del país, donde la censura, la falta de "medios" (periodísticos, editoriales y económicos) no impide, pero marca profundamente, temática, estilo y lenguaje literario. Por lo tanto, sea en el interior del Uruguay o en la "diáspora", la nueva narrativa producida en los años setenta $y$, sobre todo, la de los años ochenta ofrece características donde se precisan diferencias con la narrativa creada entre 1960 y 1973.

\section{LA PATRIA UNIVERSAL DEL ESCRITOR}

Hay quienes asumen, como Cristina Peri Rossi, el destino extraterritorial de la patria literaria universal que caracteriza la literatura del siglo XX, como un exilio inteligente. En su narrativa no son reconocibles directamente los tópicos de la literatura uruguaya, por no decir montevideana, sobre los cuales insiste un autor como Benedetti, aún viviendo fuera del país. Desde sugerencias, sobreentendidos, alusiones $\mathrm{y}$, a veces, con una simple guiñada al lector latinoamericano cómplice, Peri Rossi escribe cuentos y novelas de significado universal. Atenta lectora de la literatura italiana contemporánea y de escritores como Julio Cortázar, que supieron sintetizar una personalidad de latinoamericano universal, Peri Rossi ha ido perfeccionando "un sistema de lugares" propio que empezó con Los museos abandonados (1968) y El libro de mis primos (1969) y ha proseguido en $E l$ museo de los esfuerzos inútiles (1983),

\footnotetext{
- Ladiáspora intelectual del Uruguay de esos años es asombrosa, especialmente si se tiene en cuenta que el país tiene una población total que no llega a los tres millones de habitantes. Profesionales de todo tipo emigraron o se exiliaron en países tan diversos como los escandinavos, especialmente en Suecia, los de América Latina, sobre todo en México, Cuba y Venezuela, en España, Francia e Italia. Pero también hubo artistas e intelectuales viviendo en la República Democrática de Alemania, en Holanda y hasta en Argelia. Una Editorial surge en Estocolmo combinando un viejo esfuerzo uruguayo Comunidad del Sur - con una novedosa experiencia sueca - Nordan - mientras otro uruguayo, Tomás Stefanovics, funda una revista bilingüe en Munich, Khipú.
} 
La nave de los locos (1984) y Una pasión prohibida (1987). Su más reciente y exitoso Solitario de amor (1989) no hace sino confirmarlo, aún a través de su apertura temática.

Pero el exilio permitió además que otros autores jóvenes irrumpieran con un pie seguro en la narrativa. Sorprende la madurez de las primeras obras de ficción de Fernando Butazzoni (La noche abierta, 1984) y Raúl Salerno (Cuento contigo, 1975), el humor de Tomás Stefanovics en El divorcio (1980) y el espacio onírico de Ana Luisa Valdés, autora de un volumen de cuentos, La guerra de los albatros (1983), publicado en Estocolmo, donde ya puede reconocerse la influencia de Peri Rossi sobre promociones más jóvenes.

La experiencia europea es también gozosamente asumida por Hugo Giovanetti en Cantor de mala muerte (1986). Las andanzas bohemias de un cantor "pasaplatos" en varios países europeos y el Libano, narradas con amena desenvoltura en primera persona, demuestran que el autor de Morircon Aparicio (1986) es capaz de conciliar autoctonía y apertura universal, superando una de las antinomias de la literatura latinoamericana.

Por su parte, Matilde Bianchi, reconocida como poetisa, trasparenta su lirismo en un libro de cuentos, Originales y fotocopias (1982), premiadoy editado en España. Autores más jóvenes, como Leo Harari se aventuran desde París en la literatura testimonial, retrazando en La nostalgia tiene bolsillo (1985) una experiencia personal implicada en la tensión y la violencia de los años setenta.

En este contexto, el caso de Silvia Larrañaga con La fusión de las siluetas (1988) resulta interesante y abre nuevas perspectivas en las que se instalan los narradores de las promociones más jóvenes. Con un dominio de las técnicas narrativas del punto de vista y una capacidad para estructurar las diferentes partes del relato en una obra coherente, Larrañaga transforma el contrapunto de dos realidades, el París actual en que vive la protagonista, Maia, y el Montevideo del "pasado" al que viaja, en realidad para "descubrirlo", el fotógrafo franco-español Yves. Sin caer en detalles realistas de los escenarios aludidos, apenas insinuados en las sombras esfuminadas de paisajes donde se realza la costa de Montevideo o los vericuetos urbanos de París, una relación amorosa es evocada en la perspectiva de la distancia y, poco a poco, se diluye en los fragmentos de una novela que se graba y se escribe en forma paralela. En el resultado, donde vibra la nostalgia de un paisaje dual e inevitablemente antinómico, Montevideo y París, se comprende la imposibilidad de un destino único para quién está íntimamente roto por este desgajamiento entre su propio pasado y su presente. Si en esta ambivalencia se reconoce el destino de muchos latinoamericanos viviendo en Francia y, tal vez, el de la propia Silvia Larrañaga, lo importante es comprobar cómo se ha trascendido en una obra literaria sin fisuras, lejos de las simplificaciones de una cierta literatura del exilio.

Entre las obras escritas en el exterior, la de Saúl Ibargoyen Islas es una de las más significativas. Viviendo en México y reconocido como poeta, Ibargoyen siente la necesidad de incursionar en la narrativa. $Y$ lo hace para recuperar desde la distancia un lenguaje oral que no tiene precedentes escritos en la ficción 
uruguaya: el lenguaje del área fronteriza del norte del país, limítrofe con el Brasil y sometido a una intensa influencia de brasilerismos. Sin pintoresquismo folklórico o reivindicaciones localistas, Dbargoyen asume la lengua fronteriza en sus posibilidades de expresión integral, ósmosis apasionante de influencias y culturas en la encrucijada de dos imperios: el español y el lusitano. En dos volúmenes de relatos Fronteras de Joaquim Coluna (1975) y Los dientes del sol (1987), en las novelas La sangre interminable (1982) y Noche de espadas (1987) construye un espacio literario autónomo y cerrado, reflejo de un territorio geográfico en el que viviera en su juventud, verdadera "saga fronteriza" que ha prolongado recientemente en ¿Quién manda aquí? (1986). En esta última nouvelle denuncia los signos de la opresión a través de los mecanismos autoritarios del lenguaje militar. Sus personajes, "milicos" y centuriones, oficiales de grado bajo, brutales e ignorantes, sólo saben obedecer y mandar y transforman el lenguaje en un arma de "doble filo" con la cual se dan y se ejecutan las órdenes. Todo militar, a la excepción del grado mínimo y del más alto, tiene que manejarse en ese espectro lingüístico dual y maniqueo con el cual se obedece al superior y se manda al inferior.

\section{UN ESPACIO MITTICO CONCENTRADO}

En un país que no ha escapado a la dicotomía campo-ciudad, polarizada en la narrativa urbana y nativista de corte realista, las excepciones de la literatura fantástica o la creación de "condados", como la Santa María de Juan Carlos Onetti, han abierto nuevos sugerentes espacios narrativos. En el "ensanchamiento" del realismo tradicional y en la "fundación" de espacios míticos, se inscriben interesantes experiencias narrativas de la literatura uruguaya contemporánea.

El magisterio de Onetti, "fundador" del pueblo arquetípico de Santa María, se reconoce en los múltiples territorios míticos de intensa concentración dramática, en los espacios ensalzados por la palabra del refugio utópico de Pepe Corvina (1974) de Enrique Estrázulas, en el pueblo costero Villamar de Giovanetti Viola, en San José de las Cañas de la obra de Delgado Aparaín y en el conjunto de la obra de Juan Carlos Legido.

Creador de un mundo cerrado y de validez literaria afianzada a lo largo de más de veinte años de creación, Legido ratifica en $E l$ naufragio de la ballena (1984) y Aviso a los navegantes (1986) su apuesta a una narrativa simbólica y profundamente enraizada en la costa uruguaya, con la que integra un nuevo territorio al imaginario rioplatense. Desde Crónica de cuatro estaciones (1968) a sus relatos de tema marino con olor a salitre oceánico, se han ido delineando los contornos de una costa agreste poblada de seres desgarrados, arrojados a sus playas por el temporal de una vida, cuyos antecedentes se ignoran púdicamente. En ese pueblo mítico, en el que se reconocen los rasgos de La Paloma, puerto pesquero del departamento de Rocha, sus personajes de apellidos extranjeros se 
aferran con tenacidad a un destino uruguayo, después de haber sido vagabundos exiliados de sí mismos.

Esta misma preocupación, injertar la comarca en el mundo, para trascender lo local en lo universal sin perder los signos de unaidentidad reconocible a través de los vínculos sutiles de una atmósfera y un tono común, han guiado la estructura y la temática alegórica de los volúmenes de cuentos que he producido en el exterior y he localizado en un pueblo oceánico de la costa del este uruguayo: Las palomas de Rodrigo (1988) y Los naufragios de Malinow (1989).

\section{LAS FRONTERAS ABIERTAS DE LA REALIDAD}

Por otra parte, las fronteras de la realidad, ceñidas a la verosimilitud y al realismo tradicional en el pasado, han cedido a un "realismo ensanchado" y penetrado por loinsólito, lo extraño, el absurdo, verdadera subversión mayúscula e hiperbólica de lo real. En vez de investirse con los ropajes de lo fantástico, una serie de autores prefiere bordear los límites de lo real sin llegar a franquearlos. Al descolocarse dan a la cotidianeidad una mayor dimensión en profundidad y señalan en forma más ostensible las contradicciones de una realidad a la que se percibe básicamente como absurda.

Si los precedentes de Horacio Quiroga, José Pedro Bellán (La realidad) y el ya mencionado Felisberto Hernández deben citarse, es indudable que la necesidad de trascender el esquema dualista del realismo y lo fantástico se hace imperiosa entre los jóvenes narradores. Los ejemplos abundan, porque esta línea que se entronca con los marginales analizados anteriormente es, tal vez, la línea de mayor fuerza que se percibe en la actualidad: proyectar alegorías y mitos desde la realidad, trascender lo cotidiano por la desmesura y el absurdo, derivar conscientemente de lo colectivo a una descolocación individual.

Dividido ambiguamente entre dos mundos, Miguel Ángel Campodónico proyecta una parábola existencial en Descubrimiento del cielo(1986), ratificando una compleja dirección de indagación ética y estética anunciada en Blanco, inevitable rincón (1974) y en Dondellegue el río pardo (1980). Su obra, concebida como una alegoría del hombre contemporáneo, está teñida por un cierto pesimismo y la triste comprobación de la imposibilidad de ser feliz que parece inherente a la condición humana. Sin referencias directas al contexto de la realidad uruguaya, se pueden, sin embargo, reconocer en su obra, caracterizada por una continuidad y obsesiones reiterativas, los signos de una "metafísica existencial" rioplatense. A partir de una realidad trascendida, pero aludida, el universo de Campodónico se clausura sobre la metáfora de la propia violencia que lleva en sí el ser humano, como una condena eterna. En el mismo tono, deliberadamente asordinado, gris y entristecido, pero dejando que el humor negro desquicie todo esquema previsible, irrumpe en Instrucciones para vivir (1989) en la temática de la doble marginalidad y consiguiente alienación que da la suma de un exilio voluntario, más el ejercicio de un trabajo insólito. En una atmósfera entre irreal y grotesca, la voz del narrador oscila entre las tres 
personas del singular: la intimidad de la primera persona, la culpabilizada segunda y la distanciada tercera, aunque la obra se subtitule explícitamente: "Monólogo del sobreviviente".

En este período, Héctor Galmés publica La noche del día menos pensado (1981), Las calandrias griegas (1984), Final en borrador (1985), Necrocosmos (1986), una intensa obra creativa que se interrumpió con su muerte prematura, y Mario Levreroañade a su original producción de La ciudad (1970) la experiencia de París (1979) y de Caza de conejos (1986). Pueden citarse entre quienes cuestionan el realismo tradicional "desde adentro" algunas obras de Teresa Porzecanski, de Elvio Gandolfo (auto-calificado como "tangencial e indirecto"), pero, sobre todo, de Tarik Carson, cuya trayectoria unívoca ya ha fundado una obra de límites precisos con El hombre olvidado 1973), El corazón reversible (1986), Una pequeña soledad (1986) y Ganadores (1991).

En forma tardía, pero no menos intensa, se suma al grupo Juvenal Botto, con cuatro volúmenes de cuentos publicados en los últimos años: El sillón del poder (1985), El cuerpo del señor Olmedo (1986), Toro Mata (s.f.) y Una forma del miedo (1986). Verdadera sorpresa en un panorama literario regido por los nombres de los escritores consagrados en décadas anteriores, Botto irrumpe no sólo con una temática original en la narrativa uruguaya, "los cuentos de médicos", sesgada por lo irreal y fantástico, sino con un cuidadoso estilo, ceñido a la forma cerrada del cuento.

Autores como Alfredo Gravina y Ariel Méndez, inscritos originalmente en una narrativa realista, abren paulatinamente el espectro temático y derivan hacia la literatura fantástica o la simple paradoja, abordando otros géneros. Entre el aforismo, la anécdota, la alegoría, el chiste y hasta el poema, Ariel Méndez redondea en Ayer comí con los Borgia (1986), las características de un sub-género: el mini-cuento, en el que había incursionado con éxito en Chocolate con sardina (1982).

Paralelamente, Alfredo Gravina evoluciona de un realismo socialista puro, donde es perceptible la influencia de la narrativa rural de Enrique Amorim, Macadán (1948), Fronteras al viento (1951), Del miedo al orgullo (1959), a la alegoría "kafkiana" de la burocracia y el militarismo escrita en plena dictadura: Despegues (1974), una vertiente fantástica de su narrativa anunciada en Seis pares de zapatos (1964) donde usa la ironía desmesurada como acerbo arma de disección social.

Más recientemente, pueden mencionarse los Cuentos de atardeceres (1986) de Wilson Armas; De los espejos y lo feroces que son (1986) de Jorge Sclavo; La gran sequía (1984) de Tomás de Mattos, un escritor original que maneja con idéntica eficacia el mini-cuento y la nouvelle de largo aliento cargada de significaciones bíblicas, y Manuel Márquez, secreto y riguroso artífice de relatos de sorprendente tensión, Vacaciones de invierno (1983), inscritos en una obsesiva preocupación de defensa de una literatura donde pueda integrarse armónicamente el rigor estilístico y una temática de clara connotación contextual. De tono más intimista y moviéndose en planos entre fantásticos y reales, 
Sueño de tango (1989), del mismo Márquez, ratifica en un texto no exento de densidad las virtudes de narrador que Airiños y otros cuentos (1990) harán explícitas en la reivindicación de la saudade de los gallegos inmigrantes. Sueño de tango transcurre en un mundo de bohemia y de grupos erráticos de amigos, la rioplatense "barra", reunidos y separados por los acontecimientos de una vida que los desborda. Este "sueño" tiene, entre otros méritos, el de incorporar el lunfardo a la textualidad literaria. Márquez lo maneja con la soltura del regodeo de conocerlo y vivirlo desde adentro, pero sobre todo con la de haber decidido asumirlo como expresión válida literariamente, sin complejos ni límites.

La ambigüedad "onettiana" que tanto tienta a jóvenes escritores, permite a Claudio Invernizzi construir una obra, La pulseada (1989), alrededor de las variantes que preceden y enmarcan una derrota que se conoce desde el primer párrafo, verdadera "crónica de una derrota anunciada": la que enfrenta al protagonista Luis Piedras con un gringo, un "tal Smith", en una "pulseada". En estas variantes y al modo de un melancólico rompecabezas, se crea un universo de músicos bohemios, bares de parroquianos ociosos e inquilinatos de ventanas abiertas sobre calles bullangueras.

Otro narrador, Hugo Burel, en Esperando a la pianista y otros cuentos (1983) y El vendedor de sueños (1986), aborda también temas que flotan ambiguamente entre el realismo y lo fantástico. Los celos y las pasiones entre maniquíes fabricados con diversos materiales - yeso, cartón y plástico-mientras esperan amontonados en un depósito industrial el destino de la vidriera en que serán exhibidos, animan un universo concentrado y opresivo, desarrollado con habilidad en el espacio de un cuento, donde la crueldad y la violencia sigue siendo, pese a todo, el privilegio de los seres humanos. El amor de un enano y una mujer barbuda de un circo provincial, puesto a prueba en una alocada fuga, termina el día en que la "fenómeno" logra transformarse en una hermosa joven, es decir, un ser "normal". Esta alegoría sobre lo bello y lo monstruoso en un cuento de estilo ágil, deja espacio para la respiración irónica y el tono burlón. En estos dos ejemplos de la obra de Hugo Burel se percibe la fuerza de un mundo que ha integrado la rica herencia narrativa de Felisberto Hernández y Juan Carlos Onetti en una formulación original y propia. En ellos se ratifica, como en tantos otros autores uruguayos contemporáneos, la mirada sesgada con que la realidad es percibida, el ensanchamiento de los límites de lo verosímil por el absurdo y la irrupción de lo fantástico en la vida cotidiana.

En estos mismos años ochenta, donde nuevos autores publican sus primeros libros, hay que citar a Daniel Betancourt, autor de Como al diablo le gusta (1987) y Todas las muchachas del mundo (1986), a Guillermo Lopetegui, El rostro de Margarita Shaw (1981) y Parque de los últimos regresos (1987), autores noveles que confirman el sentido de una dirección: el ensanchamiento del realismo tradicional. Estas notas se acentúan a través de un rico lenguaje poético, pletórico de símbolos, en los cuentos de Jorge Luis Freccero, Parricidiocon granate tenue (1987), algunos de los cuales —como "El muro" - son la realización de la 
peor de las pesadillas posibles: aquéllas que se repiten cuando parece que han terminado.

\section{CATARSIS LIBERADORA Y TRADICIÓN REASUMIDA}

En la inevitable "puesta al día" literaria que toda democratización conlleva tras el paréntesis de la dictadura, no falta en la reciente producción literaria la ficción centrada en temas de represión, cárcel, tortura y las ignominias del "proceso".

\section{ENTRE EL TESTIMONIO, LA CRÓNICA Y LA HISTORIA}

El resultado de estas obras, marcado por la urgencia y el ansia de decir, cuando no de gritar, lo sucedido durante esos años, no siempre logra superar la condición de crónica y eludir el maniqueísmo impuesto por la propia realidad del testimonio. Este es el riesgo que corren en forma deliberada Hugo Giovanetti (Que se rinda tu madre , 1989), Walter de Camilli (Muñeca, 1989) y Omar Prego Gadea (Sólo para exiliados, 1987), autores que, sin embargo, tienen una obra anterior anclada en el conocimiento de los resortes de la buena literatura. Así Giovanetti Viola salva algunos cuentos gracias a la alegoría poética (por ejemplo "Ayer crucé la frontera"), mientras De Camilli se ejercita en el estilo tenso del cuento breve y en las alusiones nostálgicas al mundo de la juventud devorado por los acontecimientos. En el relato "Cartas", el protagonista llega a estar "temeroso de preguntar por los de mi generación, ya que algunos se han ido sin despedirse, otros domicilio desconocido y los más desaparecidos, engañando a los sueños y los amigos". Prego Gadea, tal vez uno de los pocos narradores en que se reconoce si no la influencia, por lo menos la complicidad con el estilo y temática cuentística de Mario Benedetti, trasciende el simple efectismo de finales a lo O'Henry que el autor de Montevideanos mecánicamente aplica a sus relatos, para hilar en los más sutiles resortes de filiación "cortazariana". La economía y claridad de su prosa, la ironía y el humor deslizados en gestos y situaciones, estructurados en la solvencia profesional del periodismo, recuerdan las mejores páginas de su olvidado Los dientes del viento (1969).

Otros escritores abordan directamente el "tiempo de pesadilla" sobre el cual sienten "la responsabilidad de atestiguar un momento insoslayable", como precisa Silvia Lago en la introducción El cuadro transparente y atros cuentos (1989) de Teresa Vázquez. Tal es el caso de Mauricio Rosencof en su narrativa testimonial, sin rencor ni pretensiones.

Por su parte, Juan Carlos Legido retraza en Quién socava los muros (1989) y a través del monólogo interior de un ministro secuestrado por la guerrilla urbana y de relatos en primera persona de militantes clandestinos y de intelectuales periféricos, el período convulsivo de la historia uruguaya que precedió el golpe de estado de 1973. Consciente del riesgo que le impone la actualidad del tema, Legido no deja de advertir en una breve introducción, la 
distancia, quince años, que separan la escritura urgida de su edición tardía. Si con ello pretende tomar una perspectiva de la que la novela carece, el texto es lo que es y no lo que el autor piensa que podría haber sido si lo hubiera escrito ahora, peaje inevitable que sólo su oficio de narrador atenúa, especialmente en el ejercicio de la escritura que refleja el "flujo de la conciencia" del secuestrado Jorge Indurain Algorta, al modo del agonizante protagonista de La muerte de Artemio Cruz de Carlos Fuentes.

Este esfuerzo por recuperar una identidad fracturada se traduce en la aparición en Uruguay, al modo de otros países latinoamericanos, de una novela histórica al "uso nostro", aunque lejos todavía de la desacralización de la historia oficial al modo de Fernando Del Paso, Abel Posse, Jorge Ibargüengoitia, Reynaldo Arenas. Se trata de las novelas históricas de Alejandro Paternain, de Milton Schinca (autor de Hombre a la orilla del mundo, sobre el exilio paraguayo de Artigas), de Tomás de Mattos (autor de ¡Bernabé, Bernabé!', sobre la figura histórica de Bernabé Rivera, y de Juan Carlos Legido, Los papeles de los Ayerza (1988).

El caso más interesante y logrado de novela entre histórica y testimonial de "la época" es A la gran muñeca (1988) de Matilde Bianchi. Una saga familiar, cubriendo cincuenta años de la historia reciente del Uruguay, sirve de pretexto para desplegar un vasto fresco de significación alegórica y de recuperación de las raíces fracturadas de la identidad nacional. En el desfile de personajes y el entrelazamiento de situaciones con que una hábil estructura novelesca va urdiendo el interés de la trama, sobresale un estilo fresco, no exento de lirismo, con que Matilde Bianchi nos recuerda su condición originaria de poeta. A la gran muñeca se abre en el optimismo de los años veinte y se cierra en los sombríos momentos que anuncian el golpe de estado de junio de 1973, cuando "la vida ya goteaba sangre y basura", en ese Montevideeo que todos "habíamos amado tanto". Más allá de los contextos reconocibles de una historia real, la dimensión novelesca aporta un sutil análisis de sentimientos y comportamientos, especialmente femeninos, donde el amor apasionado puede llegar hasta el sacrificio. Bianchi anuncia aquí la voluntad de su generación por captar la esencia de los convulsivos estremecimientos de la historia de un país que todavía no se ha resignado a la pérdida definitiva del estilo de vida que lo caracterizó hasta mediados de los años sesenta. De la no confesada nostalgia del mundo ido surge un universo narrativo, donde alternan los perfumados jardines de grandes casas en decadencia con el dolor de las heridas abiertas por la nueva violencia hasta ese momento desconocida.

\section{LA SUPERACIÓN DE LAS ANTINOMIAS}

Más allá de excepciones y atisbos de otras direcciones, es evidente que la narrativa producida en estos últimos años se esfuerza, sobre todo, por superar las tradicionales "antinomias" de la ficción nacional en particular y latinoamericana en general. A las repetidas alternativas entre realismo y 
fantasía, arraigo y desarraigo, formalismo y preocupaciones socio-políticas, nacionalismo exacerbado e internacionalismo cosmopolita, al americanismo contrapuesto al europeísmo y a las tradiciones enfrentadas a las modas importadas, con que se diferenciaron y enfrentaron las obras y los autores del pasado, la narrativa actual pretende ofrecer una síntesis donde se tenga en cuenta tanto la realidad reflejada como la forma en que se expresa literariamente. Se profundiza así en la dirección de los años sesenta, cuando por sobre cualquier compromiso político, el escritor rechazaba el facilismo maniqueo en que podría haberlo traducido.

Si la clásica dicotomía, que oponia la literatura de campo a la urbana, ha desaparecido en aras de una más compleja realidad donde las pasarelas de fondo y forma cruzan uno y otro territorio en un discurso textual que desborda el realismo y se alimenta de mitos y de pura fantasía, hay un ejercicio natural de temas y preocupaciones que sigue enraizado en la realidad rural. Enrique Williman en $E l$ sauce y otros cuentos (1989) y Angela Cáceres en algunas páginas de Tríada (1989) lo prueban para los lectores deseosos de reconocer el hálito de un mundo rural revisitado. La narrativa uruguaya, pese a sus variantes y estremecimientos, se sigue moviendo en una tradición que no ha podido ser quebrada y que parece necesita ser urgentemente recuperada.

El esfuerzo es notorio a partir de 1985, cuando muchos de los escritores viviendo en el exterior han vuelto al país. Como el Cándido de Voltaire, tras las aventuras del exilio, voluntario o forzoso, se dedican "a cultivar su jardín". Algunos se han quedado en Europa o en otros países americanos; otros optan por un voluntario ir y venir. Pero es evidente que todos han reencontrado las condiciones de un nuevo diálogo cultural.

Un diálogo que no es más que un continuum de una narrativa uruguaya caracterizada desde sus titubeantes inicios a fines del siglo XIX por una permanente vocación de atenta apertura al exterior, rápida asimilación de influencias, curiosa lectura de la producción ajena. Pese a que ciertos atisbos de regionalismo localista, por no decir chauvinista, se adivina en algunas obras, tal vez excesivamente condicionadas por los años de dictadura, aislamiento y dificultades económicas que impidieron "estar culturalmente al día", la actitud general es otra.

Hugo Burel, ya citado como cuentista, se lanza en Tampoco la pena dura (1989) a una novela que funciona en varios planos sólidamente estructurados a lo largo de más de trescientas páginas y donde retraza la agitada atmósfera de fines de la década de los años sesenta sin caer en los riesgos del testimonio directo. Una fotografía que, al modo del cuento "Las babas del diablo" de Cortázar, reproduce lo que "no se vió" pero que "estaba ahr"; en este caso el accidente del sal to de un niño desde una calesita hacia los brazos gesticulantes de su padre, los rostros borrosos de otros niños, los atónitos espectadores, sirven de pretexto y contrapunto a una acción desarticulada en que cada uno atisba la "mascarada" del mundo "según el color del cristal con que la mira". Acción directa para unos, voluntarismo extremista de otros, las sombras represivas 
que se anuncian en el horizonte, la pasiva contemplación de los más, desfilan, al modo de otra calesita - la calesita de la vida- en un dramático juego de casualidades. Apoyado en sólidos referentes culturales - "palimpsestos" citados con fruición-, y en un estilo cuidado y personal, esta novela de Burel anuncia la renovada madurez del género en un país de circuitos interrumpidos.

\section{UNA DESPREJUICIADA APERTURA AL MUNDO}

Otra tendencia interesante, y sugerente en la apertura de posibilidades narrativas que implica, es la de quienes asumen la historia reciente tratando de extraer los aspectos positivos, dejando de lado al quejoso coro de lamentaciones en que se han profesionalizado algunos autores en el exilio. Porque resulta ahora evidente que la experiencia de quienes han vivido en el exterior no ha sido siempre triste y dramática, y que muchos la han considerado como parte de un verdadero enriquecimiento personal. También el exilio, más allá de la legítima nostalgia, ha sido generador de vocaciones y ha ayudado a descubrir mundos, tan válidos como el propio. En la interdependencia cultural de lecturas, influencias y experiencias acumuladas en estos años, el resultado en la expresión literaria futura puede ser excelente. Este es el desafío que se percibe en lo inmediato: integrar positivamente estas experiencias individuales en una sociedad que se había replegadoy cerrado sobre sí misma. La próxima narrativa uruguaya lo agradecerá. Algunos buenos ejemplos ya lo demuestran.

Si ello se percibe en algunos de los relatos de Mario Delgado Aparaín, especialmente en Causa de buena muerte (1982) La balada de Johnny Sosa (1987) Teresa Porzecanski o en Julio Ricci, parece evidente en la obra dual de Hugo Giovanetti Viola, Hiber Conteris y Enrique Estrázulas, transitando con comodidad entre el localismo arraigado y el nomadismo bohemio de vocación internacional. La palabra, solemne y responsabilizada en el pasado, cede el tono grandilocuente, cuando no retórico de que se creía investida, a la crónica burlona y desacralizada de la aventura del uruguayo en el mundo, como narran el citado Cantor de mala muerte de Giovanetti, Ladrón de música (1982) de Estrázulas o la aventura cosmopolita de Hiber Conteris en La Diana en el crepúsculo (1987).

Instalada también en el mundo, la obra de Cristina Peri Rossi se ha construido sobre un complejo tejido de transtextualidades varias. Lejos de "flirtear" consciente y amablemente con el "pedantismo", como decían los enemigos de Borges, la narrativa de Peri Rossi invita a una parafernalia de palimpsestos, esa literatura en "segundo grado", arqui-textualidad, literalidad de la literatura, que nos da una intertextualidad plena de alusiones, de citas más o menos disimuladas y directas, de significados menos explícitos y distantes en títulos, subtítulos, epígrafes y notas, todo el universo del paratexto. Por ejemplo, Cosmoagonías (1989) está referido con un obvio clin d'oeuil a Cosmicómicas de Italo Calvino, cómo lo está explícitamente La nave de los locos (1984) al texto medieval y al "tapiz de la creación" de la Catedral de Gerona. Pero 
además, y sin que haya obvios referentes o citas explícitas, Peri Rossi nos recuerda una literatura universal de nombres por los que transita en pleno conocimiento de su obra: los universos cerrados y obsesivos de Kafka, Beckett y Buzzatti, las hipersensibles Virginia Woolf y Katherine Mansfield, la cruel distorsión de Flannery O'Connor, los animales simbólicos como el "tigre" en alusión a Blake en el relato "Estate violento" (incluido en La rebelión de los niños), los grandes autores de ficciones, latinoamericanos como Borges y, sobre todo, Julio Cortázar. En Peri Rossi se transita por los paisajes urbanos de los cuadros de Giorgio de Chirico, plazas vacías pobladas de estatuas vueltas de espalda, paisajes ensombrecidos, sin embargo, por la contaminación atmósferica; también penetramos en locales geométricos, poblados de las figuras hieráticas del mejor "hiper-realismo" de la pintura norteamericana contemporánea (Edward Hopper, Andy Warhol, Tom Wesselmann).

Pero más allá de méritos y reconocimientosinternacionales de una escritora como Peri Rossi, integrante de una generación anterior, es un autor joven y menos conocido quien resume el sentido potencialmente más rico de la apertura de la "comarca al mundo" que se avizora en la nueva narrativa uruguaya. Una apertura que no cede la entraña viva y raigal a un vacuo cosmopolitismo. Se trata de Fernando Loustaunau, autor de 14 (1986), una novela iniciática desenfadada y creativa, infiltrada por anglicismos y experiencias internacionales, apostando al cuestionamiento de esquemas aceptados, verdaderoBildungsroman de un joven uruguayo en Nueva York. En una novela posterior Pot-Pot (1989) Loustaunau insiste en dinamitar por la palabra, verdadera fiesta subversiva por el lenguaje a la que no nos tiene acostumbrada la narrativa uruguaya, una realidad llena de convencionalismos y estereotipos. "Novela de lenguaje" que pretende desconstruir los códigos lingüísticos/culturales que pautan la uruguayidad más ortodoxa, Pot-Pot pone en evidencia la "disglosia" del país y su condición polifónica y transcultural. Su provocación, al modo de un Burroughs o un Boukovski, pretende escandalizar, "voraginizar el discurso", "arremeter hasta las verijas del post-texto ultra-craneado", donde un sexo liberado e indiscriminado, tal como lo desencadenara en su momento Henry Miller campea como revancha contra la "moralina" de la sociedad uruguaya, "tapada" e hipócrita.

En el humor, en la desenvoltura lúdica, en la capacidad de no tomarse excesivamente en serio, en la conciencia de la relatividad histórica desde la cual se puede proyectar un destino auténtico, en la distancia con que burlonamente se miran los propios reflejos, se adivina el rumbo para una narrativa cuyas vías tradicionales parecían estar agotadas y desmentidas por la verdadera historia, aquélla que no se conoce todavía y que, muy probablemente, no se conocerá nunca. 
